\title{
LEVANTAMENTO DA PEGADA DE CARBONO DA CADEIA PRODUTIVA DO COCO BABAÇU NO ESTADO DO PIAUÍ
}

SURVEY OF THE CARBON FOOTPRINT OF THE BABAÇU COCONUT PRODUCTION CHAIN IN THE STATE OF PIAUI

\author{
AFONSO FERREIRA DE SOUZA JUNIOR | UFPI \\ FRANCISCO DE TARSO RIBEIRO CASELLI, Dr.| UFPI \\ RAFAEL DIEGO BARBOSA SOARES, Dr. | UFPI
}

\begin{abstract}
RESUMO
O coco babaçu é amplamente utilizado no estado do Piauí para a produção de alguns derivados, como o azeite de babaçu. Esses produtos possuem grande importância na economia da região e os seus processos produtivos necessitam ser estudados para serem melhorados. O objetivo desse trabalho é identificar a Pegada de Carbono associada ao processo produtivo do azeite de coco babaçu em uma empresa no Piauí. Para a quantificação das emissões foi necessário reunir dados e informações das fontes de emissões da cadeia produtiva do coco babaçu, para assim serem tratados no GEMIS 4.6, software utilizado mundialmente para o cálculo da pegada de carbono. Os resultados revelaram que esse processo possui uma Pegada de Carbono de 184, $98 \mathrm{~kg}$ de CO2eq por mês, um valor considerável bom, pois se encontra dentro da média de emissões para este tipo de atividade no estado.
\end{abstract}

PALAVRAS CHAVE: Coco babaçu; pegada de carbono; azeite

\begin{abstract}
Babaçu coconut is widely used in the state of Piaui to produce some derivatives, such as babaçu oil. These products are of great importance for the region's economy and their production processes need to be studied for improvement. The objective of this article is to identify the Carbon Footprint associated to the productive process of babaçu coconut oil in a company in Piauí. For the quantification of emissions, it was necessary to gather data and information from the emission sources to be treated in GEMIS 4.6, software used globally for the calculation of the carbon footprint. The results revealed that this process has a Carbon Footprint of 184, $98 \mathrm{~kg}$ of CO2eq per month, a good value, since it is within the average emissions for this type of activity in the state.
\end{abstract}

KEY WORDS: Babassu coconut; carbon footprint; gemis 


\section{INTRODUÇÃO}

A definição clássica de sistemas tem como representação básica o modelo composto por inputs-process-outputs (entradas- processamento - saídas) onde segundo Contador (2010) em um processo produtivo as entradas são os recursos que serão transformados no produto final, processo são o ferramental necessário para realizar essa transformação incluindo pessoas e equipamentos, saídas são os recursos já transformados. No entanto, esta definição de sistema é incompleta por considerar que os processos produtivos como sistemas perfeitos e fechados sem perdas e tendo apenas o produto final como saída.

Dentre as diversas perdas e outros tipos de saída que os sistemas produtivos podem gerar estão os resíduos e os rejeitos. Segundo Farias e Campos (2015) os resíduos podem sofrer retrabalho ou serem utilizados em algum processo e os rejeitos que é aquilo que não pode mais ser reaproveitado devendo ter destino adequado. Outro tipo de saída são as emissões gasosas de Gases de Efeito Estufa (GEE). Segundo Ribeiro et al. (2015) os GEEs são substâncias ocasionam retenção da radiação solar na atmosfera resultando no aquecimento do planeta que tem como uma de suas principais fontes os processos produtivos. Neste sentido é importante se desenvolver sistemas mais eficientes de menos poluentes de produção.

Uma das ferramentas para análise das emissões de gases do efeito estufa é a Pegada de Carbono. Segundo Wiedmann e Minxs (2008) A pegada de carbono é uma medida da quantidade total exclusivo das emissões de dióxido de carbono que é direta e indiretamente causada por uma atividade ou é acumulada ao longo dos estágios de vida de um produto. A pegada de carbono pode ser aplicada em praticamente em todos os tipos de processos produtivos, dos mais simples aos mais complexos.

Geralmente se tem uma visão que processos poluentes estão apenas ligados a grandes industriais e atividades que envolvam elevada tecnologia. Entretanto, atividades do tipo artesanal podem apresentar possibilidade de impactos ambientais devido lidarem com processos de transformação de matéria prima como no caso da pesca artesanal (SOUZA et al., 2016) e extração do óleo de dendê (BATISTA et al., 2013). Estas atividades embora tendam a ter menor impacto que as industriais devem ser melhoradas a fim da preservação do meio ambiente. Uma atividade extrativista que merece destaque é o aproveitamento do coco babaçu onde, segundo Ferrari e Soler (2015) que em sua cadeia de produção da coleta, quebra e beneficiamento gera aproximadamente cerca de 300 mil postos de trabalho no Brasil.
Segundo estudos da USP (2006) o principal produto derivado do babaçu é o óleo da sua amêndoa, que tem dentre suas utilidades servir de insumo para fabricação de óleo comestível, sabão, glicerina, margarina além da utilização da torta, sobras das amêndoas depois de retirado o óleo, para ração animal e de óleo comestível. Segundo dados do Instituto Nacional de Geografia e Estatística (IBGE) (2016) nacional o Piauí é o segundo maior produtor de babaçu perdendo apenas para o Maranhão.

Devido a importância da atividade é importante que se realize levantamento sobre as possíveis emissões de GEE no processo de aproveitamento coco babaçu. Neste sentido o presente trabalho tem por objetivo fazer o levantamento da pegada de carbono de uma empresa de extração de óleo que coco inserida na cadeia produtiva do babaçu e seus derivados no Piauí.

\section{REFERENCIAL TEÓRICO}

\subsection{Sustentabilidade}

O termo sustentabilidade (nachhaltigkeit) foi pela primeira vez empregado por Hans Carl von Carlowitz em seu Sylvicultura oeconomica, oder haußwirthliche Nachricht und Naturmäßige Anweisung zur wilden Baum-Zucht (Silvicultura econômica, ou anotações econômicas e instruções para o manejo de florestas selvagens), publicado em 1713. O autor versava sobre a necessidade de conservação e correto manejo das florestas para a manutenção da indústria de mineração na Saxônia (BOFF, 2017). Desde então, o conceito vem florescendo, atingindo seu ápice com o relatório "Limites do Crescimento" (BOFF, 2017).

O relatório Limits to Growth/Limites do Crescimento - LtG foi um documento elaborado na década de 1970 a pedido do Clube de Roma (grupo formado por personalidades notáveis na época), em que foi pensado um modelo global de demandas em face dos recursos disponíveis no planeta, bem como a relação de pressão entre estes e suas implicações na sobrevivência humana (DONELLA et al., 1972).

O relatório teve elaboração técnica do Massachusetts Institute of Technology - MIT tendo como base as interações de cinco subsistemas do sistema econômico global: a) população; b) produção de alimentos; c) produção industrial; d) poluição; e e) consumo de produtos não renováveis recursos naturais. Os resultados indicavam que se o crescimento das demandas globais continuasse no mesmo ritmo haveria um colapso global que poderia ser evitado com a mudança de comportamento econômico, tecnológico e cultural (TURNER, 2008) 
A sustentabilidade tornou-se uma questão recorrente devido aos atuais hábitos de produção e consumo. As ações dos seres humanos colocam em debate os impactos causados ao ecossistema, devido a utilização inconsciente dos recursos naturais e à grande geração de resíduos. Pena (2012) ressalta que toda atividade econômica e consequentemente, os seus impactos ambientais, são movidos pelo consumo e englobam os impactos da produção, uso e gestão de resíduos de produtos ou serviços consumidos.

Para Boff (2017) a sustentabilidade se refere a toda medida ou ação que visa a conservação de recursos energéticos, informacionais, físicos ou químicos, e que são necessários para a sobrevivência dos seres vivos. Pinto et al. (2011) resume a definição do termo sustentabilidade como o atendimento das necessidades do presente sem comprometer a possibilidade de atendimento de necessidades das próximas gerações.

Segundo Nascimento (2012) a sustentabilidade é usualmente dividida em três vertentes: ambiental, econômica e social onde: A primeira se relaciona com o equilíbrio entre os modos de produção e consumo e a base de recursos que essas atividades utilizam, garantindo uma recuperação natural dos ecossistemas no meio ambiente. A segunda sugere que haja um aperfeiçoamento e aumento da eficiência nas formas de produção e consumo, de forma a ter um uso mais consciente dos recursos naturais, permitindo uma economia em recursos como água e fontes fósseis de energia. A terceira e última vertente, a social, supõe que a sociedade possua as condições e recursos necessários para sua sobrevivência, satisfazendo suas necessidades

Para que se obtenha um desenvolvimento sustentável é importante que haja um equilíbrio entres os três setores da sustentabilidade: social, econômico e ambiental (DIAS, 2011). Esses setores se complementam, como Costa et al.. $(2012$, s.n) ressaltam, "torna-se impossível sustentar o desenvolvimento em um setor sem que os outros acompanhem este crescimento".

Tendo como base as definições e conceitos supracitados, percebe-se a necessidade de mudanças no meio industrial e comercial da sociedade atual. Sem políticas mitigatórias de geração de resíduos e uma produção mais consciente, os recursos ficarão mais escassos. Além disso, grandes impactos podem ser causados, comprometendo o bem-estar do meio ambiente e da humanidade.

Neste contexto, revela-se cada vez mais como uma prioridade o estabelecimento de políticas em relação à produção e consumo sustentáveis (PENA, 2012).

Além disso, segundo Medeiros et al.(2013, p. 42), há a necessidade de se estabelecer "mecanismos de governança tanto para a regulação de procedimentos que limitem a ação corrosiva da exploração, quanto para investimentos em potenciais de inovação e desenvolvimento favoráveis ao crescimento econômico alimentado por ações sustentáveis".

\subsection{Pegada de carbono}

Com o crescimento populacional e a evolução industrial dos países, a utilização de energia e combustíveis fósseis aumentou substancialmente, ocasionando uma maior emissão de GEE na atmosfera. Devido a esse fator, muitos países comprometidos com o Protocolo de Quioto deviam iniciar medidas de redução das suas emissões de GEE. Para tal, necessitavam da quantificação dessas emissões a fim de aplicar os métodos necessários. Um indicador utilizado e que permite o cálculo da quantidade de emissões é a Pegada de carbono (AMORIM, 2013).

Wiedmann e Minx (2008) definem a Pegada de carbono como uma medida da quantidade total de emissões de dióxido de carbono que são diretas ou indiretamente causadas por uma atividade ou ciclo de vida de um produto. Essas atividades incluem atividades de pessoas individuais, populações, empresas, indústrias etc.

A pegada de carbono é baseada na Análise de Ciclo de Vida (ACV) de produtos e processos produtivos, permitindo a visualização e o estudo para mitigar as emissões de GEE.

Essa análise no ciclo de vida permite uma visão geral, viabilizando o mapeamento e identificação dos impactos causados pelas atividades em cada etapa do processo (ANDRADE, 2010).

De acordo com Amorim (2013), diversas metodologias são utilizadas para a realização do cálculo da pegada de carbono, a escolha da metodologia utilizada dependerá do tipo de produto e da variabilidade de uma região ou país. Uma das metodologias mais utilizadas é a metodologia GHG Protocol (Greenhouse Gas Protocol).

O GHG Protocol surgiu a partir de uma associação entre o World Resources Institute (WRI) e o World Business Council for Sustainable Development (WBCSD), além de parcerias com outras instituições. Essa metodologia é compatível com as normas da International Organization for Standardization (ISO) e com as metodologias de quantificação do Painel Intergovernamental sobre Mudança Climática (IPCC). No Brasil, em 2008, foi criado o Programa Brasileiro GHG Protocol (ABNT e BID, 2013).

Os aspectos metodológicos para a identificação de fontes de emissões para posterior cálculo são apresentados nas Especificações do Programa Brasileiro GHG Protocol (2008) publicado pelo World Resources Institute (WRI). De acordo com a metodologia apresentada no Programa Brasileiro GHG Protocol, as emissões se dividem em três grandes escopos: 
Escopo 1: Emissões diretas de GEE - são emissões provenientes de fontes pertencentes à empresa ou que são controladas por ela, e podem ser subdivididas em cinco categorias: combustão estacionária, combustão móvel, emissões de processos físicos e químicos, emissões fugitivas e emissões agrícolas";

Escopo 2: Emissões indiretas de GEE de energia - nessa categoria são incluídas as emissões de GEE provenientes da compra de energia elétrica e térmica consumida pela empresa.

Escopo 3: Outras emissões indiretas de GEE - são emissões relacionadas às atividades da empresa, porém ocorrem em fontes não pertencentes à empresa ou não podem ser controladas por ela. Como exemplo tem-se: atividades relacionadas a transporte, uso de produtos acabados ou serviços, geração e descarte de resíduos etc.

A partir do cálculo de emissões de GEE, a pegada de carbono tornou-se um importante indicador ambiental para auxiliar as empresas a perceberem os impactos causados por suas atividades e a propor medidas mitigatórias para essas emissões. Segundo Weidema et al. (2008) a pegada de carbono tem potencial para ser uma boa ferramenta para o aumento da conscientização dos consumidores e geração de discussões sobre os impactos ambientais dos produtos, facilitando a difusão do pensamento sobre o ciclo de vida desses produtos.

\section{METODOLOGIA}

A produção de coco babaçu e seus derivados é uma atividade importante na economia do estado do Piauí e vem sendo desenvolvida em algumas regiões do estado.

Este estudo tendo como objetivo calcular a Pegada de Carbono desse processo produtivo e para a realização dessa quantificação, basicamente, serão seguidas as três etapas a seguir: Delimitação do campo de atuação da pesquisa; Escolha da metodologia de quantificação da pegada de carbono e Análise crítica dos resultados.

Na etapa de delimitação, ocorrerá o rastreamento e desenho da cadeia produtiva do coco babaçu e derivados, tanto por aporte bibliográfico quanto por observação em locais de produção. A partir dessa identificação da cadeia produtiva é possível elencar todas as atividades e tarefas relacionadas à cadeia, podendo dessa forma identificar e selecionar os fatores de emissão direta e indireta de gases de efeitos estufa. Para Amorim (2013), as emissões diretas de GEE são provenientes de fontes controladas pela empresa e as indiretas são uma consequência das atividades da empresa que acontecem em fontes não controladas por ela.

Para realizar a quantificação das emissões de GEE, será seguida a metodologia abordada pelo GHG Protocol (WRI e WBSCD), uma ferramenta mundialmente utilizada para inventariar e quantificar emissões de GEE. Segundo o GHG Protocol (WRI e WBSCD), os passos as seguir são utilizados para inventariar emissões.

- Identificar as fontes de emissão de GEE;

- Selecionar uma metodologia de cálculo para as emissões de GEE;

- Recolher dados das atividades e selecionar os fatores de emissão;

- Aplicar as ferramentas de cálculo;

- Registrar os dados de emissão de GEE

Tendo como base o processo de produção do azeite de babaçu, algumas informações devem ser coletadas a fim de identificar as fontes de emissão e calcular a pegada de carbono. As variáveis do processo que devem ser identificadas e registradas estão apresentadas a seguir:

- Informações sobre o uso de combustíveis e distâncias percorridas no transporte de matéria-prima

- Consumo de eletricidade e/ou combustíveis em máquinas e equipamentos

- Uso de produtos químicos na fabricação do azeite ou no cultivo do coco babaçu

- Utilização de produtos descartáveis, como, por exemplo, embalagens.

Após a identificação das fontes de emissão é necessário classificá-las segundo o seu âmbito e categorias de fonte, conceitos que foram abordados no referencial teórico. O cálculo da quantificação de emissões é desenvolvido segundo os parâmetros estabelecidos pela metodologia para cada categoria de emissão. Os valores obtidos são calculados e representados em kgCO2eq.

Para o auxílio no desenvolvimento do cálculo, a ferramenta escolhida foi o software GEMIS 4.6. Segundo Andrade e Matos 2011, quanto às emissões de GEE, "o software GEMIS reúne fatores de emissão fornecidos por instituições de renome, muitas das quais seguem a metodologia IPCC, sendo reconhecido por alguns como o software padrão internacional para esta finalidade".

Uma vez determinados os valores das emissões relacionadas à produção dos derivados do coco babaçu será realizada uma análise crítica dos resultados encontrados a fim de propor medidas de mitigação ou eliminação de emissões no processo produtivo.

\section{RESULTADOS E DISCUSSÕES}

A produção do óleo/azeite de coco babaçu, em sua maioria, ainda acontece de forma muito manual, principalmente a etapa de colheita dos cocos.

Algumas indústrias utilizam equipamentos para acelerar o processo de produção do azeite e auxiliarem no 
processo de separação dos componentes do coco babaçu: epicarpo, mesocarpo, endocarpo e amêndoas. Para este trabalho, foram elencados os equipamentos utilizados nas indústrias Piauí que processam o coco babaçu para a produção de azeite.

As etapas para a fabricação do óleo podem ser descritas na Figura 1.

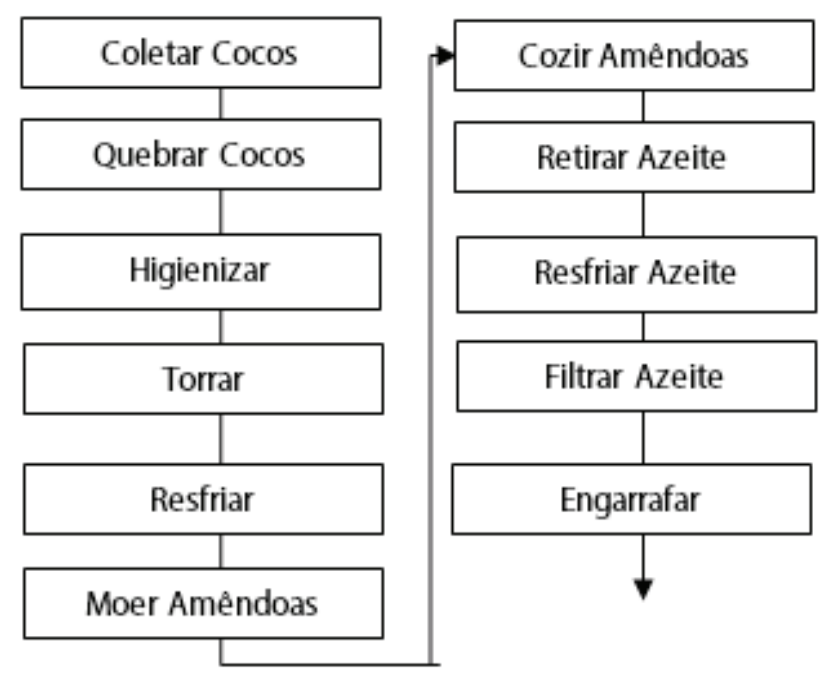

Figura 1: Etapas de produção do azeite de coco babaçu Fonte: Rocha e Caselli (2015)

Esses equipamentos são os que contribuem para o quantitativo da Pegada de Carbono desse processo produtivo, pois fazem a utilização de energia elétrica. De acordo com a literatura, a energia elétrica se caracteriza como fonte de emissão indireta de GEE. As emissões relacionadas às etapas de cozimento e torragem também participam da Pegada de Carbono da produção de azeite, mas os dados não puderam ser aferidos para que fosse realizado o cálculo dessas emissões.

Os equipamentos utilizados na produção e os dados de sua utilização são descritos na Tabela 1 a seguir. A base apresentada para a utilização dos equipamentos foi uma capacidade de processamento de $80 \mathrm{~kg}$ de coco babaçu por dia durante um mês de funcionamento.

\begin{tabular}{|l|l|l|l|}
\hline $\begin{array}{l}\text { Equipamentos } \\
\text { coco babaçu }\end{array}$ & Pot.W & Hrs/mês & $\begin{array}{l}\text { Total KWh/ } \\
\text { mês }\end{array}$ \\
\hline $\begin{array}{l}\text { Serrador } \\
\text { de cocos }\end{array}$ & 2238 & 53,4 & 119,5092 \\
\hline $\begin{array}{l}\text { Lixadeira } \\
\text { de cocos }\end{array}$ & 1119 & 120 & 134,28 \\
\hline $\begin{array}{l}\text { Peneira } \\
\text { vibratória }\end{array}$ & 186,5 & 26,4 & 4,9236 \\
\hline
\end{tabular}

Tabela 1: Dados de equipamentos da produção de azeite Fonte: Autores
Por se tratar de uma produção no Brasil, o software Gemis calcula as emissões indiretas por utilização de energia elétrica são baseadas na produção de energia por hidrelétricas. Os dados de emissões são fundamentados na utilização dos equipamentos e os valores são apresentados em uma proporção de kg/KWh. Esses valores estão descritos na Tabela 2.

\begin{tabular}{|l|l|}
\hline $\begin{array}{l}\text { Fatores de emissão para energia } \\
\text { hidrelétrica segundo o Gemis }\end{array}$ & $\mathbf{k g} / \mathbf{K W h}$ \\
\hline Co2eq & 0,715 \\
\hline $\mathrm{CO} 2$ & 0,31 \\
\hline $\mathrm{CH} 4$ & 0,0135 \\
\hline
\end{tabular}

Tabela 2: Fatores de emissão para energia hidrelétrica Fonte: Autores

Os valores de emissão obtidos são os dos gases de efeito estufa $\mathrm{CO} 2$ e CH4, e também o valor de CO2eq, unidade utilizada na quantificação da Pegada de Carbono.

Esses valores são representados por equipamento na Tabela 3, assim como o total de emissões.

\begin{tabular}{|l|l|l|l|}
\hline $\begin{array}{l}\text { Equipamentos } \\
\text { coco babaçu }\end{array}$ & CO2eq $(\mathbf{k g})$ & CO2 $(\mathbf{k g})$ & CH4 $(\mathbf{k g})$ \\
\hline $\begin{array}{l}\text { Serrador } \\
\text { de cocos }\end{array}$ & 85,44907 & 37,0478 & 1,6133742 \\
\hline $\begin{array}{l}\text { Lixadeira } \\
\text { de cocos }\end{array}$ & 96,0102 & 41,6268 & 1,81278 \\
\hline $\begin{array}{l}\text { Peneira } \\
\text { vibratória }\end{array}$ & 3,520374 & 1,52631 & 0,0664686 \\
\hline Total & 184,9796 & 80,2009 & 3,4926228 \\
\hline
\end{tabular}

Tabela 3: Valores de emissão dos equipamentos Fonte: Autores

Portanto, como apresentado na tabela acima, a Pegada de Carbono do processo produtivo de azeite de coco babaçu é estimada em 184, $98 \mathrm{~kg}$ de CO2eq por mês. Esse valor seria ainda maior se houvesse os dados de emissões provenientes das etapas de cozimento e torragem.

\section{CONCLUSÃO}

A Pegada de Carbono é uma ferramenta que auxilia as empresas a entender e dimensionar os impactos causados por suas atividades e dessa forma encontrar meios de mitigar essas emissões, tendo assim uma melhor responsabilidade social ambiental. No caso do processo produtivo do azeite de coco babaçu, a Pegada de Carbono foi estimada em 184, 98 kg de CO2eq por mês, um valor considerado bom, devido ao fato de estar dentro da média 
de emissões desse tipo atividade no estado do Piauí. Isso justifica-se pela natureza mais artesanal do processo produtivo, não tendo tantas fontes de emissão em comparação com outros processos. Uma forma de diminuir ainda mais esse quantitativo seria a utilização equipamentos mais modernos que acelerem ainda mais os procedimentos, necessitando de uma menor utilização de energia elétrica na produção.

Este tipo de estudo da produção de azeite no Piauí é importante para que as empresas do estado possam avaliar e otimizar seus processos, tornando-se mais competitivas no mercado. Além disso, revela a importância do estudo e a quantificação da Pegada de Carbono para processos maiores, de grandes empresas, e que causam um maior impacto ao meio ambiente com suas emissões de GEE.

\section{REFERÊNCIAS}

ABNT - ASSOCIAÇÃO BRASILEIRA DE NORMAS TÉCNICAS; BID - BANCO INTERAMERICANO DE DESENVOLVIMENTO. Guia Metodológico para a Realização de Inventários em Emissões de Gases de Efeito Estufa - Rio de Janeiro, RJ: 2013. 30p.

AMORIM, D. A. L. A. Pegada de Carbono de uma Empresa Produtora de Eletricidade de Fontes Engenharia Mecânica). Faculdade de Engenharia da Universidade do Porto. Porto, 2013.

ANDRADE, R. T. A pegada de carbono como um dos indicadores de sustentabilidade para medição da responsabilidade socioambiental empresarial: um estudo de caso na unidade sede da Petrobras em Natal-RN. 2010. 214 f. Dissertação (Mestrado em Engenharia de Produção). Universidade Federal do Rio Grande do Norte. Natal, 2010.

BOFF. L. Sustentabilidade: o que é: o que não é: Vozes, Petrópolis, 2017.

COSTA, C. R. R.; MOTKE, F. D.; KNEIPP, J. M.; FRIZZO, K.; MADRUGA, L. R. R. G. A preocupação socioambiental no contexto empresarial. Revista Educação Ambiental em Ação, n. 28, ano X, fev. 2012. Disponível em: < http://www.revistaea.org/artigo.php?idartigo=1175 > . Acesso: 15 fev. 2016.

DIAS, Reinaldo. Gestão ambiental: responsabilidade social e sustentabilidade. 2 ed. São Paulo: Atlas, 2011. DONELLA, H. et al. The limits to growth. New York: Universe, 1972.. Disponível em: http://www.donellameadows.org/wp-content/userfiles/Limits-toGrowth-digital-scanversion.pdf Acesso em: 23 nov. 2018 Capítulo V

Fundação Getúlio Vargas. Centro de Estudos em Sustentabilidade da EAESP (2008). Programa Brasileiro GHG Protocol. Especificações do Programa Brasileiro GHG Protocol: Contabilização, Quantificação e Publicação de Inventários Corporativos de Emissões de Gases de Efeito Estufa (Segunda Edição). Fundação Getúlio Vargas \& World Resources Institute.

MEDEIROS, A.; SOUZA, E.; FRANZIN, S.; ALMEIDA F.; SOUZA, C.. Desenvolvimento e sustentabilidade ambiental: análise das diretrizes da política nacional de desenvolvimento Regional. Linkania. v. 1, n. 7, pág. 36 $-57,2013$.

NASCIMENTO, Elimar Pinheiro do. Trajetória da sustentabilidade: do ambiental ao social, do social ao econômico. Estud. av., São Paulo, v. 26, n. 74, p. 51-64, 2012. Disponível em: <http:// www.scielo.br/scielo.php?script $=$ sci_arttext\&pi$\mathrm{d}=$ S0103-40142012000100005\&lng =en\&nrm=iso $>$. Acesso: 14 nov. 2016.

PENA, Ana Margarida Carvalho. Sustentabilidade Ambiental da Alimentação Humana. 2012. 89f. Tese (Doutorado em Ciências da Nutrição). Faculdade de Ciências da Nutrição e Alimentação da Universidade do Porto. Universidade do Porto.

PINTO, B. D. L. et al. Indicadores de desenvolvimento sustentável para caracterização de melhoria contínua em processos de certificação ambiental. Meio Ambiente Industrial, São Paulo, 92 ed., ano XVI, p. 18-28, 2011.

WIEDMANN, Thomas; MINX, Jan. A definition of 'carbon footprint'. Ecological economics research trends, v. 1, p. 1-11, 2008.

ROCHA, Y. C. N.; CASSELI, F. T. R. Análise dos indicadores de qualidade da produção do azeite de coco babaçu em Teresina - PI. Relatório de pesquisa, UFPI, 2015.

TURNER, Graham M. A comparison of The Limits to Growth with 30 years of reality. Global environmental change, v. 18, n. 3, p. 397-411, 2008. Disponível em: https://www.sciencedirect.com/science/article/pii/ S0959378008000435 Acesso em: 23 nov. 2018. 


\section{AUTORES}

ORCID: HTTPS://ORCID.ORG/0000-0002-7344-0715

AFONSO FERREIRA DE SOUZA JUNIOR | Curso de Bacharelado em Eng. de Produção | Universidade Federal do Piauí UFPI, Teresina (PI), Brasil | Correspondência: Universidade Federal do Piauí - UFPI Campus Universitário Ministro Petrônio Portella Bairro Ininga - Teresina - PI - Bloco 09 Coord. Eng. de Produção - CEP: 64049-550 CT | e-mail: afonsojuniorcx@gmail.com

Orcid: https://orcid.org/0000-0002-8654-6551

FRANCISCO DE TARSO RIBEIRO CASELLI, Dr. | Curso de Doutorado em Ciência Ambientais PRODEMA em Rede | Universidade Federal do Piauí - UFPI | Teresina (PI)- Brasil | Correspondência: Universidade Federal do Piauí - UFPI Campus Universitário Ministro Petrônio Portella Bairro Ininga - Teresina - PI - Bloco 09 Coord. Eng. de Produção CEP: 64049-550 CT | e-mail: tarso.caselli@ufpi.edu.br

Orcid: https://orcid.org/0000-0002-6623-2977

RAFAEL DIEGO BARBOSA SOARES, Dr. | Curso de Doutorado em Ciência Ambientais PRODEMA em Rede | Universidade Federal do Piauí - UFPI, Teresina (PI), Brasil. | Correspondência: Universidade Federal do Piauí - UFPI Campus Universitário Ministro Petrônio Portella Bairro Ininga - Teresina - PI - Bloco 09 Coord. Eng. de Produção CEP: 64049-550 CT | e-mail: rafaeldiegobarbosa@hotmail. com

\section{COMO CITAR ESTE ARTIGO}

SOUZA JR., Afonso Ferreira; CASELLI, Francisco de Tarso Ribeiro; SOARES, Rafael Diego Barbosa. Levantamento Da Pegada De Carbono Da Cadeia Produtiva Do Coco Babaçu No Estado Do Piauí. MIX Sustentável, [S.I.], v. 7, n. 1, p. 73-80, dez. 2020. ISSN 24473073. Disponível em:<http://www.nexos.ufsc.br/index.php/ mixsustentavel>. Acesso em: dia mês. ano. doi:https:// doi.org/10.29183/2447-3073.MIX2020.v7.n1.73-80.

DATA DE ENVI0: 07/04/2020

DATA DE ACEITE: 29/09/2020 
